\title{
It's the Amount of Thought that Counts: When Ambivalence Contributes to Mammography Screening Delay
}

\author{
Suzanne C. O'Neill, PhD, \\ Lombardi Comprehensive Cancer Center, Georgetown University
}

Isaac M. Lipkus, PhD,

Duke University, School of Nursing

Jennifer M. Gierisch, PhD, MPH,

Duke University Medical Center, Division of General Internal Medicine, Durham Veteran Affairs Medical Center, Center for Health Services Research in Primary Care

Barbara K. Rimer, DrPH, and UNC Gillings School of Global Public Health, University of North Carolina, Chapel Hill

J. Michael Bowling, PhD

UNC Gillings School of Global Public Health, University of North Carolina, Chapel Hill

\section{Abstract}

Purpose-This study examines whether ambivalence towards mammography screening, as moderated by total amount of thought given to the reasons for and against getting mammograms at recommended intervals, predicts greater delay in obtaining subsequent screening mammograms.

Methods-A sample of 3,430 insured women with recent (within the last 8-9 months) screening mammograms completed telephone interviews as part of a five year intervention study to achieve sustained adherence to annual-interval mammography. Delay was assessed by the number of days between mammograms.

Results-Controlling for demographic factors and perceived screening barriers, days between mammograms increased as ambivalence and thought increased. Thought moderated ambivalence: among women who were most ambivalent, women obtained mammograms a month earlier for each unit increase in thought.

(C) 2009 Jacobs Institute of Women's Health. Published by Elsevier Inc. All rights reserved

Reprint Address: S. C. O'Neill, Ph.D., Cancer Control Program, Lombardi Comprehensive Cancer Center, 3300 Whitehaven St., NW, Suite 4100, Washington, DC 20007. T: 202-687-0869 F: 202-687-0305 sco4@ georgetown.edu.

Co-authors contact information: Dr. Isaac M. Lipkus, 905 West Main Street, Box 34, Durham, NC 27701, T: 919-956-5232, F: 919-956-7451, isaac.lipkus@duke.edu

Dr. Jennifer M. Gierisch, Durham VA Medical Center, HSR\&D (152), 508 Fulton Street, Durham, NC 27705, T: 919-286-0411 x

5655, F: 919-416-8025, j.gierisch@duke.edu

Dr. Barbara K. Rimer, Dean's Office - 170 Rosenau Hall, UNC Gillings School of Global Public Health, 135 Dauer Drive, Campus Box 7400, Chapel Hill 27599-7400, T: 919-966-3215, F: 919-966-7678, brimer@unc.edu

Dr. J. Michael Bowling, 309 Rosenau Hall, 135 Dauer Drive, Campus Box 7440, 27599-7440, USA, T: 919-302-8166, F:

919-928-8955, jbowling@email.unc.edu

Publisher's Disclaimer: This is a PDF file of an unedited manuscript that has been accepted for publication. As a service to our customers we are providing this early version of the manuscript. The manuscript will undergo copyediting, typesetting, and review of the resulting proof before it is published in its final citable form. Please note that during the production process errors may be discovered which could affect the content, and all legal disclaimers that apply to the journal pertain.

Financial Disclosures: The authors have no conflicts of interest to report. 
Conclusion-Future studies should test innovative ways to resolve ambivalence and increase thought about consequences of getting mammograms as a strategy to promote mammography screening adherence.

\section{Keywords}

Mammography; ambivalence; thought; maintenance

In the U.S. last year, an estimated 192,370 women were diagnosed with breast cancer; 40,170 died from the disease (ACS, 2010). Along with advances in adjuvant care, mammography screening remains an important means of reducing disease-related morbidity and mortality (Jemal et al., 2010; Kalager et al., 2010). However, renewed controversies and other issues may prompt some women, and possibly, some clinicians, to rethink the benefits of mammography, resulting in ambivalence about getting screened at all as well as the schedule on which women should be screened (USPSTF, 2009; Mandelblatt et al., 2009; Partridge \& Winer, 2009; Truog, 2009; Quanstrum \& Hayward, 2010; Welch, 2010). Ambivalence, defined as holding both positive and negative attitudes towards an object, in this case, mammography (Cacioppo \& Berntson, 1994; Jonas \& Ziegler, 2007), may have contributed to the slight downturn in mammography use in the U.S. (Centers for Disease Control and Prevention, 2007; Miller et al., 2009). Indeed, greater screening-related ambivalence is associated with lower rates of adherence to recent colon and breast cancer screening (Lipkus \& Klein, 2006; Halabi, Skinner, Samsa, Strigo, Crawford, \& Rimer, 2000).

Feeling ambivalent can be uncomfortable (Clark et al., 2008). This discomfort may motivate resolution of ambivalence (Newby-Clark, McGregor, \& Zanna, 2002). Specifically, from a stress and coping perspective (Lazarus, 1991; Lazarus \& Folkman, 1984), the emotional discomfort associated with ambivalence may serve as a cue to engage and cope with a potentially stressful event (Larsen, Hemenover, Norris \& Cacioppo, 2003; Haenze, 2001; Lazarus, 1991; Luce, 1998; Luce, Payne \& Bettman, 2001; Wenzel, Glanz, \& Lerman, 2002; Jonas, Diehl, \& Bromer, 1997; Maio, Esses, \& Bell, 1996; van Harreveld et al., 2009). To cope with ambivalence and related negative emotions, these women may distance themselves from thinking about and having mammograms. Conversely, women may try to resolve ambivalence by spending time thinking about reasons for and against getting mammograms at recommended intervals as a means of problem-focused coping (Jonas, Broemer, \& Diehl, 2000). Women who raise more reasons for (rather than against) getting their next mammograms on recommended schedules should be more likely to get screened. These processes are consistent with findings which show that people with greater ambivalence process messages more extensively, especially if these messages are perceived by recipients to reduce ambivalence (Clark et al., 2008). Thinking about potential reasons for and against getting mammograms on recommended schedules may be one way that women resolve their mammography-related ambivalence.

We conducted a five year intervention study to achieve sustained adherence to annualinterval mammography in a sample of 3,430 women that began as currently-adherent (DeFrank et al., 2009; Gierisch et al., 2010a). We examined how ambivalence toward mammography screening, moderated by the total amount of thought given to reasons for and against getting mammograms at recommended intervals, influenced receipt of subsequent screening mammograms among women with recent (within the last 8 to 9 months) screening mammograms. Our research aim in the present study was to assess the impact of ambivalence, total thought and interaction of ambivalence and thought on number of days between two consecutive screening mammograms in a sample of insured women. As we have done in previous reports (Gierisch et al., 2010a), we used days between mammograms 
as our outcome. This option is more sensitive to smaller variations in adherence than a dichotomous outcome (Gierisch et al., 2010b). We tested three hypotheses.

H1 With increasing levels of ambivalence, women would spend more time thinking about positive consequences of getting and negative consequences of not getting their next screening mammograms.

H2 Greater levels of baseline ambivalence and total amount of thought given to reasons for and against getting mammograms at recommended intervals would predict greater delay in obtaining women's next screening mammograms.

H3 Thought would moderate ambivalence, such that at increasing levels of ambivalence, more time spent thinking about reasons for and against getting mammograms would predict fewer days between women's next screening mammograms.

\section{Methods}

\section{Participants}

Data for these analyses are from Personally Relevant Information about Screening Mammography (PRISM) that took place from 2003 to 2008. Study eligibility and recruitment are described elsewhere (DeFrank et al., 2009; Gierisch et al., 2009, 2010a). Briefly, eligible women from the parent study were North Carolina residents enrolled with the North Carolina State Health Plan for Teachers and State Employees (SHP) for two or more years prior to sampling, had no personal history of breast cancer, and were between ages of 40 and 75 . To ensure uniform adherence to mammography upon study enrollment, we invited women who had screening mammograms 8 to 9 months before study entry. We enrolled 3,547 women into PRISM who completed baseline telephone interviews. All measures reported here are baseline measures. For this report, we conducted analyses on 3,430 PRISM participants; 20 women were excluded, because they had their next mammograms less than 10 months (304 days) after their previous mammograms. Thus, these subsequent mammograms probably were not for routine screening. Fifty-two women were excluded from these analyses, because there were too few women in groups other than white and African American. An additional 45 women were excluded due to item nonresponse on key predictor and outcome variables used for these analyses. As part of PRISM, all participants received reminders two to three months prior to their mammography due dates. See DeFrank et al. (2009) and Gierisch et al. (2010a) for background on interventions. This study was approved by the Biomedical Institutional Review Boards of [blinded by WHI editors].

\section{Measures: Baseline Predictor Variables}

Sociodemographics-We collected baseline data on age, race $(1=$ White, $0=$ African American $)$, educational attainment $(1=$ college graduate/post graduate, $0=$ some college/ technical school, high school graduate/not completing high school), and perceived financial hardship $(1=$ money available after paying bills for special things, $0=$ little or no spare money available after paying bills; Williams et al., 1992).

Ambivalence about Mammography-We examined the role of felt rather than potential for ambivalence. Whereas potential for ambivalence indexes the underlying degree of inconsistency (conflict) between positive and negative beliefs, felt ambivalence captures the actual experience of this conflict. Modeled after questions used previously in mammography research (Halabi et al., 2000; Lipkus \& Klein, 2006), ambivalence was measured by agreement with two statements: 1) You have mixed feelings about whether you 
should get another mammogram when you are due; and 2) You are torn about whether you should get a mammogram when you are due (4-point scale, Strongly disagree-strongly agree). The items were correlated at $.60(p<.0001)$ and summed (range $2-8)$.

Amount of thought-Participants indicated how often during the last week they thought about: 1) benefits you could gain from having a mammogram when you are due, and 2) benefits you could lose if you did not have a mammogram when you are due. Response options were: none of the time, a little of the time, a moderate amount of time, and most of the time. These strongly correlated items $(r=.79 ; p<.0001)$ were summed (range $2-8)$.

Perceived barriers to mammography-We assessed 10 closed-ended barriers to mammography use (Champion, 1999; Champion \& Skinner, 2003; Rimer et al., 1989). Each participant was asked, "I am going to read you a list of reasons some women say have delayed their getting mammograms. For each reason, please tell me if it could delay you getting a mammogram when you are due." Response options were strongly agree, somewhat agree, somewhat disagree, strongly disagree. We considered barriers present if participants endorsed somewhat or strongly agree for any barrier. Barriers then were summed.

\section{Outcome Variable}

Days between mammograms-Our outcome was the number of days between mammograms. We counted the number of days between participants' eligibility mammograms, which occurred 8 to 9 months before study entry, and their next screening mammograms. A calculated variable counted number of days until receipt of subsequent mammograms; counting ceased when women received subsequent mammograms.

We assessed mammography screening through a combination of health insurance claims data and self-report. If a discrepancy occurred, self-report dates were used, as claims data can sometimes be incomplete due to lag time in claims processing, women's paying out of pocket or filing claims with alternate insurance (DeFrank et al., 2009; Gierisch et al., 2010a). Previous research has shown that self-reports are a valid measure of recent mammograms, especially for women in healthcare organizations and over short recall periods (e.g., Rauscher, et al., 2008).

\section{Data Analyses}

After examining descriptive statistics, including variable distributions and the bivariate correlation between ambivalence and thought, we used multivariable linear regression (MLR) analysis using SAS PROC GLM to examine the impact of total thought, ambivalence, and the interaction of thought and ambivalence on a count of elapsed days between successive mammograms. We controlled for sociodemographics (race, age, education, and income), total number of self-reported barriers to obtaining mammograms, and PRISM intervention arms in regression analyses. We probed interaction effects between thought and ambivalence using methods described by Aiken and West (1991) and Bauer and Curran (2005).

\section{Results \\ Sample Characteristics}

Most women were white, aged $\geq 50$, college educated, married or living as married and did not report financial hardship (Table 1). On average, participants did not spend much time thinking about the positive and negative consequences of getting/not getting their next mammograms when due. Most women were not very ambivalent about mammography ( mean $=2.2$, range $=2-8)$ and reported few barriers (mean $=0.7$; range $=0-10)$. 


\section{Multivariable Model Predicting Days Between Mammograms}

Table 2 presents MLR regression coefficients and standard errors examining the relationship between total thought, ambivalence, and the interaction of thought and ambivalence, controlling on socio-demographics, arm of the study, and barriers. Although ambivalence was unrelated to total thought $(r=-.02, p=0.35)$, we found support for our other hypotheses. Specifically, main effects of both ambivalence and thought were positive. The interaction was negative, indicating an attenuating effect of thought with increasing values of ambivalence.

\section{Probing of MLR 2-Way Interaction}

To further assess this interaction effect, we plotted the simple slopes and intercepts to examine the impact of thought at three values of ambivalence (2, 4, and 6) (See Figure 1). The lower bound of the region of significance is -1.2 , below the minimal value of the distribution of thought. The upper bound of the region of significance is 2.3 , well within the distribution of total thought (range 2-8). With increasing levels of ambivalence, increased thought was related to fewer days between mammograms. For example, women obtained mammograms one-half month (15.7 days) earlier for each unit increase in total thought at an ambivalence level of $4(\mathrm{t}=-2.40, \mathrm{p}<.05)$. Women received mammograms a month $(29.9$ days) earlier for each unit of thought change at an ambivalence level of $6(t=-2.3, p<.05)$.

\section{Discussion}

Prior studies have shown that people who feel ambivalent about cancer screening are less likely to be screened (Halabi et al., 2000; Lipkus \& Klein, 2006). This study replicates this pattern of findings for obtaining consecutive screening mammograms. These findings extend prior research by including examination of an effect modifier, amount of thought devoted to considering positive and negative consequences of getting/not getting women's next mammograms on schedule. Among women who were most ambivalent about getting their next mammograms on schedule, those who thought more about the consequences had significantly fewer days between consecutive screening mammograms-a full month fewer -compared to those who considered consequences less often. This effect was significant even after controlling for demographic factors and barriers, known contributors to screening delay (O'Malley et al., 2002; Champion, 1994; Maxwell \& Bradford, 1996; Partin \& Slater, 2003; Blanchard et al., 2004; Rakowski et al., 2004; Bobo et al., 2004). While the clinical impact on personal and population health of a one month delay in screening mammography is unknown, cumulative delays over the course of an individual woman's lifetime or in the population as a whole may impact disease-related morbidity and mortality (Mandelblatt et al., 2009; Partridge \& Winer, 2009). This is true whether the screening schedule is annual or biennial mammography.

Ambivalence may contribute to the recent downturn in mammography use nationally (Centers for Disease Control and Prevention, 2007). Women who feel more ambivalent about screening may represent an important, reachable target group for mammography screening intervention efforts. Indeed, the main effect for ambivalence was quite strong. Notably, given that at baseline women in our sample were adherent to mammography, it is not surprising that most had low levels of ambivalence. Ambivalence may be an even more important factor for non-adherent women and for other screening and treatment choices (colorectal cancer screening, prenatal screening, prostate cancer treatment), in which people may feel greater ambivalence (Sapp et al. 2010; Bungay \& Cappello, 2009; Lipkus et al., 2003). We might expect that there would be greater ambivalence about screening tests that are not as well-diffused across populations as mammography. 
While we are aware of no interventions that incorporate strategies to reduce ambivalence and increase deliberative thought, having (highly) ambivalent women reflect upon their reasons for getting mammograms shares many similarities to interventions designed to promote mammography adherence. These include interventions that encourage women to consider the pros and cons of mammography, both with and without clinician support (Champion et al., 2003, 2006; Lauver et al., 2003; Rakowski et al., 2003; Russel et al., 2010; Vernon et al., 2008), as well as Motivational Interviewing (Costanza et al., 2009) and decision aid interventions (O'Connor, Stacey, Entwistle, Llewellyn-Thomas, Rovner, Holmes-Rovner et al., 2003). Decision aids are most beneficial for patients who experience decisional conflict. Their effects may be the result of patients becoming actively engaged in such processes as value clarification and weighing of decisional pros and cons (O'Connor, Fiset, DeGrasse, Graham, Evans, Stacey et al., 1999). Engaging people to think of reasons to perform recommended behaviors may be of greatest benefit to those who are most ambivalent or have the greatest decisional conflict (Schwartz et al., 2009). Indeed, ambivalence shares commonalities with constructs such as decisional balance (Prochaska \& DiClemente, 1983; Rakowski et al., 1997) and decisional conflict (O'Connor et al., 1999, 2003).

This study has limitations. First, we did not manipulate ambivalence experimentally; no causal relationships can be inferred. Indeed, it might be ethically inappropriate to induce ambivalence in this context. Second, we used a rather crude measure of thought because we were constrained by the number of questions we could ask. Whether a more sophisticated measure would have yielded different results should be examined. Nonetheless, we found support for our thought measures. Women who reported thinking more about the consequences of getting/not getting their next mammograms on schedule generated more open-ended responses when asked about these consequences. Third, we assessed only thinking about the benefits gained by getting mammograms and the benefits lost by not getting mammograms; such thoughts facilitate reasons for engaging in screening. We did not assess amount of thought and content related to perceived negative consequences of getting mammograms and perceived benefits gained by not undergoing screening as well.

Finally, our sample has limitations. PRISM's design required all women to have health insurance coverage and recent mammograms prior to study entry. Our purpose was to improve sustained adherence, as part of the NIH Health Maintenance Consortium (Ory et al., 2010). Our results cannot be generalized outside of these groups. Overall, women were well-educated, and representation of black women and other racial and ethnic minorities in the parent study was modest. This may have been a function of eligibility criteria but cannot be confirmed (DeFrank et al., 2007). Further examination of these constructs in more diverse samples is needed.

Despite these limitations, our study adds to a small, growing body of research about the relationship between ambivalence and health behaviors, specifically, mammography. Our results suggest that women who are ambivalent about mammography may be an important target group for intervention. While even for mammography, ambivalence may be highly skewed, ambivalence may be very important for those women who are ambivalent about the screening procedure. Strategies that facilitate thinking about the consequences of mammography should be considered; explicit tests of such interventions would be needed.

\section{Acknowledgments}

The authors thank UNC team members Deborah Usinger and Tara Strigo for their work on the project. We are grateful to Ingrid Morris, MPH, and Don Bradley, MD, of BlueCross BlueShield of North Carolina; and Nancy Henley, MD, MPH, and Casey Herget, MPH, MSW, of the North Carolina State Health Plan and our participants for making this research possible. 
This study was supported by 5R01 CA105786 from the National Cancer Institute (PI: Rimer). Suzanne O'Neill was supported by American Cancer Society Grant MRSG-10-110-01-CPPB. At the time of these analyses, Dr. Gierisch was funded by the Agency for Healthcare Research and Quality (grant 2T32HS000079).

\section{References}

Aiken, LS.; West, SG. Multiple Regression: Testing and interpreting interactions. Thousand Oaks: Sage; 1991.

American Cancer Society. Cancer Facts \& Figures 2010. Atlanta: American Cancer Society; 2010.

Bauer DJ, Curran PJ. Probing interactions in fixed and multilevel regression: Inferential and graphical techniques. Multivariate Behavioral Research. 2005; 40:373-400.

Bobo JK, Shapiro JA, Schulman J, Wolters CL. On-schedule mammography rescreening in the National Breast and Cervical Cancer Early Detection Program. Cancer Epidemiology Biomarkers and Prevention. 2004; 13:620-630.

Blanchard K, Colbert JA, Puri D, Weissman J, Moy B, Kopans DB, et al. Mammographic screening: patterns of use and estimated impact on breast carcinoma survival. Cancer. 2004; 101:495-507. [PubMed: 15274062]

Bungay H, Capello R. "As long as the doctors know what they are doing": Trust or ambivalence about patient information among elderly men with prostate cancer? European Journal of Cancer Care. 2009; 18:470-476. [PubMed: 19473376]

Cacioppo JT, Berntson GG. Relationship between attitudes and evaluative space: A critical review with emphasis on the separation of positive and negative substrates. Psychological Bulletin. 1994; 115:401-423.

Centers for Disease Control and Prevention. Use of mammograms among women aged $>40$ years-United States, 2000-2005; Morbidity and Mortality Weekly Report. 2007. p. 49-51.

Champion V. Relationship of age to mammography compliance. Cancer. 1994; 74:329-335. [PubMed: 8004604]

Champion V. Revised susceptibility, benefits, and barriers scale for mammography screening. Research in Nursing \& Health. 1999; 22:341-348. [PubMed: 10435551]

Champion V, Skinner CS. Differences in perceptions of risk, benefits, and barriers by stage of mammography adoption. Journal of Women's Health. 2003; 12:277-286.

Champion V, Maraj M, Hui S, Perkins AJ, Tierney W, Menon U, Skinner CS. Comparison of tailored interventions to increase mammography screening in nonadherent older women. Preventive Medicine. 2003; 36:150-158. [PubMed: 12590989]

Champion VL, Springston JK, Zollinger TW, Saywell RM, Monahan PO, Zhao Q, Russell KM. Comparison of three interventions to increase mammography screening in low income African American women. Cancer Detection and Prevention. 2006; 30:535-544. [PubMed: 17110056]

Clark JK, Wegener DT, Fabrigar LR. Attitudinal ambivalence and message-based persuasion: motivated processing of proattitudinal information and avoidance of counterattitudinal information. Personality and Social Psychology Bulletin. 2008; 34:565-577. [PubMed: 18340037]

Costanza ME, Luckmann R, White MJ, Rosal MC, Lapelle N, Cranos C. Moving mammogramreluctant women to screening: a pilot study. Annals of Behavioral Medicine. 2009; 37:343-349. [PubMed: 19517203]

DeFrank, JT.; Bowling, JM.; Rimer, BK.; Gierisch, JM.; Skinner, CS. [Retrieved October 1, 2010] Triangulating differential nonresponse by race in a telephone survey. Preventing Chronic Disease. 2007 July. from http://www.cdc.gov/pcd/issues/2007/jul/06_0102.htm

DeFrank JT, Rimer BK, Gierisch JM, Bowling JM, Farrell D, Skinner CS. Impact of mailed and automated telephone reminders on receipt of repeat mammograms: A randomized controlled trial. American Journal of Preventive Medicine. 2009; 36:459-467. [PubMed: 19362800]

Gierisch JM, O'Neill SC, Rimer BK, DeFrank JT, Bowling JM, Skinner CS. Factors associated with annual-interval mammography for women in their 40s. Cancer Epidemiology. 2009; 33:72-78. [PubMed: 19481879] 
Gierisch JM, DeFrank JT, Bowling JM, Rimer BK, Matuszewski JM, Farrell D, et al. Finding the minimal intervention needed for sustained mammography adherence. American Journal of Preventive Medicine. 2010a; 39:334-344. [PubMed: 20837284]

Gierisch JM, Reiter PL, Rimer BK, Brewer NT. Standard definitions of adherence for infrequent yet repeated health behaviors. American Journal of Health Behavior. 2010b; 34:669-679. [PubMed: 20604693]

Haenze M. Ambivalence, conflict, and decision-making: Attitudes and feelings in Germany towards NATO's military intervention in the Kosovo war. European Journal of Social Psychology. 2001; 31:693-706.

Halabi S, Skinner CS, Samsa GP, Strigo TS, Crawford YS, Rimer BK. Factors associated with repeat mammography screening. Journal of Family Practice. 2000; 49:1104-1112. [PubMed: 11132060]

Jemal A, Ward E, Thun M. Declining death rates reflect progress against cancer. PLoS One. 2010; 5:e9584. [PubMed: 20231893]

Jonas, K.; Broemer, P.; Diehl, M. Attitudinal ambivalence. In: Stroebe, W.; Hewstone, M., editors. European Review of Social Psychology. London: John Wiley and Sons; 2000. p. 35-74.

Jonas K, Diehl M, Bromer P. Effects of attitudinal ambivalence on information processing and attitude-intention consistency. Journal of Experimental Social Psychology. 1997; 33:190-210.

Jonas, K.; Ziegler, R. Attitudinal ambivalence. In: Hewstone, M.; Schut, H.; de Wit, J.; Van Den Bos, K.; Stroebe, M., editors. The scope of social psychology: Theory and applications. New York: Psychology Press; 2007. p. 29-42.

Larsen, JT.; Hemenover, SH.; Norris, CJ.; Cacioppo, JT. Turning adversity to advantage: On the virtues of the coactivation of positive and negative emotions. In: Aspinwall, L.; Staudinger, U., editors. A psychology of human strengths: Fundamental questions and future directions for positive psychology. Washington, DC: American Psychological Association; 2003. p. 211-226.

Lauver DR, Settersten L, Kane JH, Henriques JB. Tailored messages, external barriers, and women's utilization of professional breast cancer screening over time. Cancer. 2003; 97:2724-2735. [PubMed: 12767084]

Lazarus RS. Progress on a cognitive-motivational-relational theory of emotion. American Psychologist. 1991; 46:819-834. [PubMed: 1928936]

Lazarus, RS.; Folkman, S. Stress, appraisal, and coping. New York: Springer; 1984.

Lipkus IM, Klein WM. Effects of communicating social comparison information on risk perceptions for colorectal cancer. Journal of Health Communication. 2006; 11:391-407. [PubMed: 16720537]

Lipkus IM, Green LG, Marcus A. Manipulating perceptions of colorectal cancer threat: Implications for screening intentions and behaviors. Journal of Health Communication. 2003; 8:213-228. [PubMed: 12857652]

Luce MF. Choosing to avoid: Coping with negatively emotion-laden consumer decisions. Journal of Consumer Research. 1998; 24:409-433.

Luce, MF.; Payne, JW.; Bettman, JR. The impact of emotional tradeoff difficulty on decision behavior. In: Weber, E.; Baron, J.; Loomes, G., editors. Conflict and tradeoffs in decision-making. Cambridge, United Kingdom: Cambridge University Press; 2001. p. 86-109.

Maio GR, Bell DW, Esses V. Ambivalence and persuasion: The processing of messages of immigrant groups. Journal of Experimental Social Psychology. 1996; 32:513-536. [PubMed: 8979932]

Mandelblatt JS, Cronin KA, Bailey S, Berry DA, de Koning HJ, Draisma G, et al. Effects of mammography screening under different screening schedules: model estimates of potential benefits and harms. Annals of Internal Medicine. 2009; 151:738-747. [PubMed: 19920274]

Maxwell ABR, Bradford C. Predictors of interval mammography screening: results of a longitudinal study. Journal of Women's Health. 1996; 5:343-349.

Miller JW, King JB, Ryerson AB, Eheman CR, White MC. Mammography use from 2000 to 2006: state-level trends with corresponding breast cancer incidence rates. AJR. American Journal of Roentgenology. 2009; 192:352-360. [PubMed: 19155394]

Newby-Clark IR, McGregor I, Zanna MP. Thinking and caring about cognitive inconsistency: when and for whom does attitudinal ambivalence feel uncomfortable? Journal of Personality and Social Psychology. 2002; 82:157-166. [PubMed: 11831406] 
O’Connor AM, Fiset V, DeGrasse C, Graham ID, Evans W, Stacey D, et al. Decision aids for patients considering options affecting cancer outcomes; Evidence of efficacy and policy implications. Monographs of the National Cancer Institute. 1999; 25:67-80.

O'Connor AM, Stacey D, Entwistle V, Llewellyn-Thomas H, Rovner D, Holmes-Rovner M, et al. Decision aids for people facing health treatment or screening decisions. Cochrane Database of Systematic Reviews. 2003; 2 CD001431.

O'Malley AS, Forrest CB, Mandelblatt J. Adherence of low-income women to cancer screening recommendations. Journal of General Internal Medicine. 2002; 17:144-154. [PubMed: 11841530]

Ory MG, Lee Smith M, Mier N, Wernicke MM. The science of sustaining health behavior change: The health maintenance consortium. 2010

Partin MR, Slater JS. Promoting repeat mammography use: insights from a systematic needs assessment. Health Education and Behavior. 2003; 30:97-112. [PubMed: 12564670]

Partridge AH, Winer EP. On mammography-more agreement than disagreement. New England Journal of Medicine. 2009; 361:2499-2501. [PubMed: 19940286]

Preacher KJ, Curran PJ, Bauer DJ. Computational tools for probing interactions in multiple linear regression, multilevel modeling, and latent curve analysis. Journal of Educational and Behavioral Statistics. 2006; 31:437-448.

Prochaska JO, DiClemente CC. Stages and processes of self-change of smoking: toward an integrative model of change. Journal of Consulting and Clinical Psychology. 1983; 51:390-395. [PubMed: 6863699]

Rakowski W, Andersen MR, Stoddard AM, Urban N, Rimer BK, Lane DS, et al. Confirmatory analysis of opinions regarding the pros and cons of mammography. Health Psychology. 1997; 16:433-441. [PubMed: 9302540]

Rakowski W, Lipkus IL, Clark MA, Rimer BK, Ehrich B, Lyna PR, Kornguth PJ. Reminder letter, tailored stepped-care, and self-choice comparison for repeat mammography. American Journal of Preventive Medicine. 2003; 25:308-314. [PubMed: 14580632]

Rakowski W, Breen N, Meissner H, Rimer BK, Vernon SW, Clark MA, et al. Prevalence and correlates of repeat mammography among women aged 55-79 in the Year 2000 National Health Interview Survey. Preventive Medicine. 2004; 39:1-10. [PubMed: 15207980]

Rauscher GH, Johnson TP, Cho YI, Walk JA. Accuracy of self-reported cancer-screening histories: a meta-analysis. Cancer Epidemiology, Biomarkers \& Prevention. 2008; 17:748-757.

Rimer BK, Keintz MK, Kessler HB, Engstrom PF, Rosan JR. Why women resist screening mammography: patient-related barriers. Radiology. 1989; 172:243-246. [PubMed: 2740510]

Russell KM, Champion VL, Monahan PO, Millon-Underwood S, Zhao Q, Spacey N, Rush NL, Paskett ED. Randomized trial of the lay health advisor and computer intervention to increase mammography screening in African American women. Cancer Epidemiology Biomarkers and Prevention. 2010; 19:201-210.

Sapp JC, Hull SC, Duffer S, Zornetzer S, Sutton E, Marteau TM, Biesecker BB. Ambivalence toward undergoing invasive prenatal testing: An exploration of its origins. Prenatal Diagnosis. 2010; 30:77-82. [PubMed: 19924734]

Schwartz MD, Valdimarsdottir HB, DeMarco TA, Pehskin BN, Lawrence W, Rispoli J, et al. Randomized trial of a decision aid for BRCA1/BRCA2 mutation carriers: impact on measures of decision making and satisfaction. Health Psychology. 2009; 28:11-19. [PubMed: 19210013]

Truog RD. Screening mammography and the "r" word. New England Journal of Medicine. 2009; 361:2501-2503. [PubMed: 19940292]

U.S. Preventive Services Task Force. Screening for breast cancer: U.S. Preventive Services Task Force recommendation statement. Annals of Internal Medicine. 2009; 151:716-726. W-236. [PubMed: 19920272]

Van Harreveld F, vander Plight J, de Liver YN. The agony of ambivalence and ways to resolve it: Introducing the MAID Model. Personality and Social Psychology. 2009; 13:45-51.

Vernon SW, del Junco DJ, Tiro JA, Coan SP, Perz CA, Bastian LA, Rakowski W, Chan W, Lairson DR, McQueen A, Fernandez ME, Warrick C, Halder A, DiClemente C. Promoting regular mammography screening II. Results from a randomized controlled trial in US women veterans. 2008 
Wenzel, L.; Glanz, K.; Lerman, C. Stress, coping, and health behavior. In: Glanz, K.; Rimer, B.; Lewis, F., editors. Health behavior and health education: Theory, research and practice. 3rd ed. San Francisco: Jossey-Bass; 2002. p. 210-239.

Williams RB, Barefoot JC, Califf RM, Haney TL, Saunders WB, Pryor DB, et al. Prognostic importance of social and economic resources among medically treated patients with angiographically documented coronary artery disease. JAMA. 1992; 267:520-524. [PubMed: 1729574] 


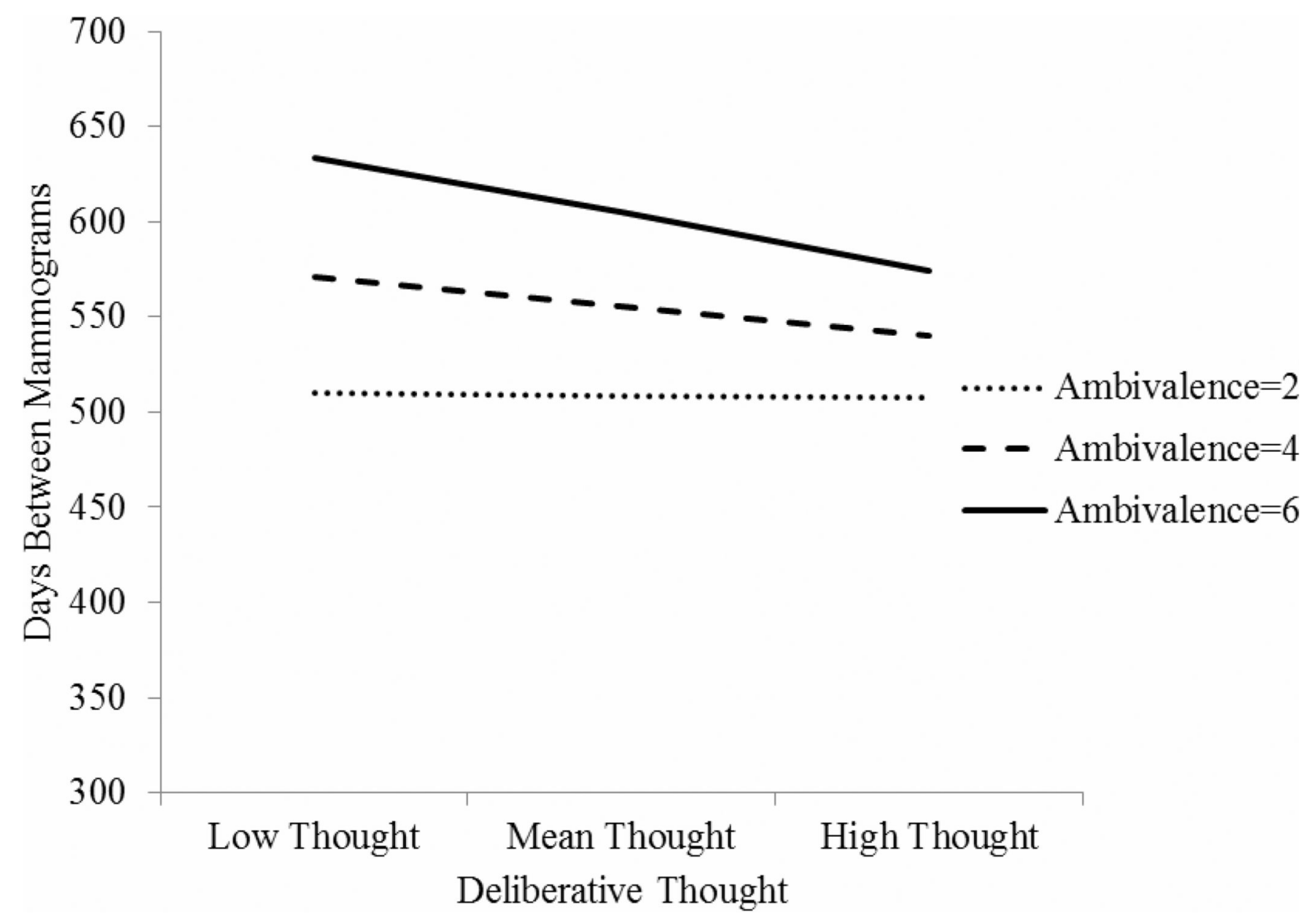

Figure 1. Interaction Effects of Ambivalence and Total Thought on Days Between Mammograms $(\mathbf{n}=3430)$

Note. All analyses controlled for arm of research study, education, race, family finances, age, educational attainment and number of self-reported barriers to obtaining mammograms. 
Table 1

Sample Characteristics $(\mathrm{n}=3,430)$

\begin{tabular}{|c|c|c|}
\hline$\underline{\text { Variable }}$ & $\%$ & $\mathbf{M}(\mathbf{S D})$ \\
\hline Age & & $54.7(6.3)$ \\
\hline \multicolumn{3}{|l|}{ Race } \\
\hline White & 89.6 & \\
\hline Black & 10.4 & \\
\hline \multicolumn{3}{|l|}{ Education } \\
\hline Less than college & 37.2 & \\
\hline College graduate & 62.8 & \\
\hline \multicolumn{3}{|l|}{ Perceived financial hardship } \\
\hline After paying bills, has money for special things & 63.8 & \\
\hline Has money to pay bills, but little spare money & 28.9 & \\
\hline Has money to pay bills due to cutback on things & 5.3 & \\
\hline Has difficulty paying bills no matter what & 2.0 & \\
\hline \multicolumn{3}{|l|}{ Intervention categories } \\
\hline Usual Care Reminder & 24.0 & \\
\hline \multicolumn{3}{|l|}{ Enhanced Letter Reminder } \\
\hline + BarriCon Call $(+)$ & 9.4 & \\
\hline \multicolumn{3}{|l|}{ Enhanced Letter Reminder } \\
\hline + BarriCall & 9.0 & \\
\hline \multicolumn{3}{|l|}{ Enhanced Letter Reminder } \\
\hline + BarriCon Call(-) & 9.7 & \\
\hline \multicolumn{3}{|l|}{ Enhanced Letter Reminder } \\
\hline + Control Group & 9.8 & \\
\hline \multicolumn{3}{|l|}{ Automated Telephone Reminder } \\
\hline + BarriCon Call(+) & 9.6 & \\
\hline \multicolumn{3}{|l|}{ Automated Telephone Reminder } \\
\hline + BarriCall & 9.9 & \\
\hline \multicolumn{3}{|l|}{ Automated Telephone Reminder } \\
\hline + BarriCon Call(-) & 9.4 & \\
\hline \multicolumn{3}{|l|}{ Automated Telephone Reminder } \\
\hline + Control Group & 9.2 & \\
\hline Felt ambivalence & & $2.2(0.8)$ \\
\hline Total thought (benefits gained and lost) & & $3.0(1.6)$ \\
\hline Total perceived barriers to screening & & $0.7(0.8)$ \\
\hline Days from baseline to 12 month mammogram & & $442.6(162.2)$ \\
\hline Percent Adherent (305-425 days between successive mammograms) & 74.9 & \\
\hline
\end{tabular}


Table 2

Multivariable OLS Regression Predicting Interval in Days between Baseline and 12 Month Mammograms $(\mathrm{n}=3430)$

\begin{tabular}{|c|c|c|}
\hline Variable & Coefficient (SE) & t-value \\
\hline Intercept & $558.9(32.9)$ & --- \\
\hline Total thought & $13.3(5.5)$ & $2.4^{*}$ \\
\hline Felt ambivalence & $45.8(8.0)$ & $5.8^{* * *}$ \\
\hline Interaction between thought and ambivalence & $-7.2(2.4)$ & $-3.0^{* *}$ \\
\hline Total perceived barriers to screening & $21.7(3.6)$ & $6.0^{* * *}$ \\
\hline Age & $-2.8(0.44)$ & $-6.7^{* * *}$ \\
\hline \multicolumn{3}{|l|}{$\underline{\text { Education }}$} \\
\hline Less than college & Referent & \\
\hline College graduate & $-11.0(5.8)$ & -1.89 \\
\hline \multicolumn{3}{|l|}{$\underline{\text { Financial situation }}$} \\
\hline Greater financial hardship & Referent & \\
\hline After paying bills, enough money for special things & $-30.0(5.9)$ & $-5.1^{* * *}$ \\
\hline \multicolumn{3}{|l|}{$\underline{\text { Race }}$} \\
\hline Black & Referent & \\
\hline White & $-27.4(5.9)$ & $-3.1^{* *}$ \\
\hline
\end{tabular}

Note. All analyses control for arm of research study.

$* 0.05$

$* * \quad p<.01$

$* * *$

$p<.001$. 